\title{
RECONTEXTUALIZAÇÕES NO DISCURSO DA ESTRATÉGIA DE SAÚDE DA FAMÍLIA
}

(Recontextualizations in the discourse of the Family Health Strategy)

\author{
Izabel Magalhães ${ }^{1}$ \\ (Universidade de Brasília - UnB/Universidade Federal do Ceará - UFC)
}

\begin{abstract}
The purpose of this paper is to analyze the notion of 'recontextualization' in light of data from an ethnographic-discursive research in the Family Health Strategy (ESF, previously National Health Program) of the Brazilian National Health System (SUS). This notion, which is appropriated in Critical Discourse Analysis (CDA), according to Fairclough (2003, 2010) and van Leeuwen (2008), has a lot to say about the different ways in which health professionals and patients view health care. The present approach is based on interviews, focal groups and research narratives, and the final remarks point to different ways of recontextualizing the ESF caring practice by participants.
\end{abstract}

Keywords: Recontextualization, hybridism, social practice, Brazilian National Health System (SUS).

\section{RESUMO}

O objetivo deste artigo é analisar o conceito de 'recontextualização' à luz de dados de uma pesquisa etnográfico-discursiva na Estratégia de Saúde da Família (ESF, anteriormente Programa de Saúde da Família) do Sistema Nacional de Saúde (SUS). O conceito, que é apropriado pela Análise de Discurso Crítica (ADC), segundo Fairclough (2003, 2010) e van Leeuwen (2008), tem muito a dizer sobre as diferentes maneiras de percepção da atenção à saúde por profissionais de saúde e pacientes. A presente abordagem baseia-se em entrevistas, grupos focais e relatos de pesquisa, e as considerações finais indicam diferentes formas de recontextualização por participantes da prática assistencial da ESF.

Palavras-chave: Recontextualização; hibridismo; prática social; Sistema Único de Saúde (SUS).

\section{INTRODUÇÃO}

O objetivo deste artigo é analisar o conceito de 'recontextualização' em dados de uma pesquisa etnográfico-discursiva financiada pelo PPSUS/CNPq/FUNCAP/SESA - Edital 3/2012. Esta análise busca relacionar recontextualização a hibridismo na perspectiva de Lopes (2005) e Ball (2001). O conceito de 'recontextualização', com origem na sociologia da educação, foi desenvolvido por Bernstein (1990). Recontextualização significa:

a apropriação de elementos de uma prática social por outra, situando a primeira no contexto da última e transformando-a de formas particulares nesse processo. (FAIRCLOUGH, 2003, p. 32).

A recontextualização ocorre nos dados deste estudo quando profissionais de saúde e

\footnotetext{
${ }^{1}$ Professora do Programa de Pós-Graduação em Linguística da UnB (Pesquisadora Colaboradora) e da UFC (Professora Visitante). Ph. D. em Linguística e Pós-Doutora pela Lancaster University, Lancaster, Reino Unido.
} 
pacientes discorrem a respeito de questões relacionadas à saúde. A apropriação da prática social da Estratégia de Saúde da Família (ESF) do Sistema Único de Saúde (SUS) faz-se de forma diferenciada entre os próprios profissionais (médicos, enfermeiros, dentistas, técnicos de enfermagem e agentes comunitários de saúde) e entre os pacientes. Nesse sentido, a recontextualização implica diferentes interpretações. De acordo com Gomes:

Um mesmo aspecto do mundo pode ser representado de diferentes formas em um mesmo texto ou gênero produzido por uma mesma instituição ou instituição diferente (GOMES, 2010, p. 299).

Essas diferentes interpretações e representações materializam-se em diferentes escolhas linguísticas. Por exemplo, enquanto a dra. Paola descreve a ESF como "um atendimento sistematizado, né, que tem A DEMANDA LIVRE a gente atende a demanda livre e atende uma demanda programada e atende através de grupos, né, grupos de diabético, grupo de crianças, gestantes sempre em conjunto com a equipe”, a enfermeira Lúcia faz o seguinte comentário: "o programa de saúde da família que agora é estratégia de saúde da família, ele tem a... o objetivo de-de fazer um-um criar um vínculo entre a saúde e a população, então cada equipe é responsável por uma determinada área, certo, e toda aquela população que reside ali é de responsabilidade dos profissionais da equipe." (As convenções de transcrição dos dados são apresentadas na Seção 2.) Cada uma das profissionais de saúde interpreta e representa a prática da ESF de maneira diferente.

Apesar de ter origem no estruturalismo ${ }^{2}$ e em oposições binárias, como natureza vs. cultura, é possível associar a recontextualização à perspectiva do hibridismo cultural contemporâneo, se entendermos as diferentes interpretações que fazem parte do processo de recontextualização como possibilidades de ruptura e ressignificações na construção discursiva das identidades (MAGALHÃES, 2010).

No mundo contemporâneo, que alguns entendem como modernidade posterior (GIDDENS, 1991), há uma tendência de mescla de gêneros discursivos e textos, que afeta a construção das identidades. Embora com perspectivas diferentes, Fairclough (2010, 2003) e Blommaert (2005) tratam dessa questão, o primeiro com o conceito de 'ordem do discurso', introduzido por Foucault (1996); e o segundo, com o conceito de 'ordem de indexicalidade'. De acordo com Fairclough, a ordem do discurso é formada de elementos: discursos, gêneros

\footnotetext{
${ }^{2}$ Conforme Lopes (2005, p. 61), “o estruturalismo em seu sentido estrito designa o movimento intelectual que se desenvolveu particularmente na França, nos anos 1960, em torno da linguística, da antropologia, da filosofia, da política e da psicanálise. Trata-se de uma tentativa anti-positivista de investigar o real se afastando do vivido, de forma a conhecer suas estruturas, especialmente construídas pela linguagem.”
} 
discursivos e estilos, que correspondem aos significados representacional, acional e identificacional. Fairclough relaciona os significados do discurso às macrofunções da linguagem de Halliday (1994). Enquanto a Representação está ligada à função 'ideacional', a Ação aproxima-se da função 'interpessoal', mas enfatizando o texto "como forma de (inter)ação nos eventos sociais", e incorporando a Relação, isto é, "a realização de relações sociais" (Fairclough, 2003, p. 27); e a Identificação liga-se à função 'interpessoal' ${ }^{3}$

Uma ordem do discurso é uma rede de práticas sociais em seu aspecto linguístico. Os elementos de ordens do discurso não são coisas como nomes e frases (elementos de estruturas linguísticas), mas discursos, gêneros e estilos [...] Esses elementos selecionam determinadas possibilidades definidas pelas línguas e excluem outras - eles controlam a variabilidade em áreas particulares da vida social. Dessa forma, as ordens do discurso podem ser consideradas a organização social e o controle da variação linguística (FAIRCLOUGH, 2003, p. 24). ${ }^{4}$

Ao passar das estruturas abstratas aos eventos concretos, é muito difícil separar a linguagem de outros elementos sociais. Na terminologia de Althusser, a linguagem passa a ser sobredeterminada por outros elementos sociais (ALTHUSSER E BALIBAR, 1970). Assim, no nível das estruturas abstratas, o(a) analista pode falar mais ou menos exclusivamente sobre a linguagem - mais ou menos - por que as teorias 'funcionais' da linguagem concebem mesmo as gramáticas das línguas como socialmente moldadas (HALLIDAY, 1978) (FAIRCLOUGH, 2010, pp. 294-295).

Cabe observar dois pontos sobre o conceito de ordem do discurso na Teoria Social do Discurso de Fairclough: 1) o controle de sua estruturação social; 2) a sobredeterminação da linguagem nesse nível intermediário de redes de práticas, em relação às estruturas sociais, que são "entidades abstratas que definem potenciais, isto é, conjuntos de possibilidades" (FAIRCLOUGH, 2010, p. 294). Portanto, os eventos sociais, como o atendimento à população por profissionais de saúde, são mediados pela ordem do discurso. Como diz Foucault:

Primeira questão: quem fala? Quem, no conjunto de todos os sujeitos falantes, tem boas razões para ter esta espécie de linguagem? Quem é seu titular? [...] A fala médica não pode vir de quem quer que seja; seu valor, sua eficácia, seus próprios poderes terapêuticos e, de maneira geral, sua existência como fala médica não são dissociáveis do personagem, definido por status, que tem o direito de articulá-lo, reivindicando para si o poder de conjurar o sofrimento e a morte (FOUCAULT, 1987, pp. 57-58).

\footnotetext{
${ }^{3}$ Não discutirei a representação nos termos de Alencar (2013), pois sua crítica deixa de considerar os sentidos da representação como discurso na perspectiva faircloughiana, detendo-se no conceito histórico do termo.

${ }^{4}$ Todas as traduções neste artigo são minhas, a não ser que seja especificado de outra forma.
} 
Dessa forma, quando a dra. Bruna, participante deste estudo, diz "a atenção primária de saúde é uma estratégia válida no sentido de promoção, prevenção e cuidados de atenção primária, tendeu?", ela fala como profissional médica, e sua linguagem é sobredeterminada pela prática médica.

Agora, vejamos o conceito de ordem de indexicalidade. Blommaert define esse conceito como "significados sistemicamente reproduzidos, estratificados, frequentemente denominados 'normas' ou 'regras' de linguagem, e sempre tipicamente associados a formas particulares de linguagem (ex., o 'padrão', a variedade de prestígio, a forma usual de ter uma conversa com amigos, etc.)" (BLOMMAERT, 2005, p. 73). De acordo com o investigador, é preciso entender que os sistemas sociais organizam a desigualdade entre as pessoas pela "atribuição de diferentes significados indexicalizados às formas linguísticas" (ibid.), por exemplo, atribuindo um valor inferior ao uso de variedades dialetais e um valor superior ao uso da variedade de prestígio.

Os significados indexicalizados são ligações ordenadas entre os signos linguísticos e os diversos contextos sociais. Essas indexicalidades estruturadas "ocorrem na forma de complexos estratificados em que a alguns tipos de indexicalidades são atribuídas posições superiores a outros, sugerindo prestígio vs. estigma; racionalidade vs. emoção; pertencimento a um grupo particular vs. não pertencimento, e assim por diante" (BOMMAERT, 2005, p. 74).

Como vemos, embora Blommaert faça mais referência à linguagem do que ao discurso, os dois conceitos guardam em comum a ideia da estruturação social da linguagem. Nesse ponto, seria mais indicado falar do discurso, que Fairclough (2009, p. 163) define da seguinte forma: "uma forma de construir aspectos do mundo associada a uma perspectiva social particular".

Apesar de fazer uma crítica à Analise de Discurso Crítica (ADC), Blommaert deixa de considerar a contribuição da vasta obra de Fairclough. De qualquer forma, não é meu propósito aqui discutir a crítica, pois, no meu modo de ver, falta aos comentários de Blommaert o reconhecimento de que a ADC é um campo de estudos heterogêneo.

De modo geral, o conceito de ordem do discurso é mais desenvolvido do que o de ordem de indexicalidade. Também, ao considerar a construção social efetivada pelo discurso, o conceito de Fairclough é mais consistente do que o de Blommaert. É, portanto, a ordem do discurso que controla as possibilidades de recontextualização e ressignificação das práticas sociais de saúde, que se caracterizam por atos discursivos e não-discursivos por atores sociais 
associados ao contexto de prevenção de doenças (Magalhães et al., 2014).

Pode-se abordar a recontextualização em termos da intertextualidade, isto é, da interrelação entre textos, da maneira como "os textos dialogam com outros textos" (Fairclough, 2003, p. 17). Quando há a incorporação de outros textos num determinado texto, os textos podem ser atribuídos a um autor ou autora, ou não.

A abordagem de van Leeuwen (2008) é também de recontextualização de práticas sociais. O autor considera práticas sociais como "modos socialmente regulados de realizar coisas" (van Leeuwen, 2008, p. 6). Acrescenta van Leeuwen:

Diferentes práticas sociais são 'reguladas' em diferentes graus e em diferentes modos - por exemplo, mediante prescrição rígida, ou pelas tradições, ou por influência de especialistas, ou modelos carismáticos de papéis, ou por restrições dos recursos tecnológicos usados, e assim por diante (van LEEUWEN, 2008, p. 7).

Há semelhanças entre o conceito de prática social de van Leeuwen (2008) e o de Fairclough (2003). Porém, o conceito de Fairclough é mais dinâmico do que o de van Leeuwen, ao acrescentar o aspecto da organização das práticas em redes:

Práticas sociais podem ser pensadas como modos de controlar a seleção de determinadas possibilidades estruturais e a exclusão de outras, e a retenção dessas seleções em áreas particulares da vida social, ao longo do tempo. As práticas sociais são organizadas juntas em redes de formas específicas e transformadoras (FAIRCLOUGH, 2003, pp. 23-24).

Neste artigo, adoto o conceito de Fairclough (2003), que me permite abordar práticas do tipo mosaico, que se relacionam entre si e podem ser recontextualizadas em seu hibridismo (FAIRCLOUGH, 2001). Interessa-me aqui entender as práticas de saúde que são recontextualizadas por profissionais de saúde e pacientes, que destacam aspectos distintos, fluidos, e mesmo contraditórios.

Este artigo está dividido em três seções, além desta Introdução e das Considerações finais. Na Seção 1, “A Estratégia de Saúde da Família (ESF)”, discorro sobre este programa do Sistema Único de Saúde (SUS), enquanto na Seção 2 apresento a pesquisa "O Diálogo como Instrumento de Intervenção de Profissionais da Saúde na Relação com Pacientes". A Seção 3, "Recontextualizações e ressignificações na Estratégia de Saúde da Família", é a análise de dados da pesquisa.

\section{A Estratégia de Saúde da Família (ESF)}


Trata-se de um programa do Sistema Único de Saúde (SUS), que tem como propósito a promoção de saúde e a prevenção de doenças. Para a dra. Paola, citada na Introdução, a ESF oferece "atendimento sistematizado", com uma demanda livre e uma demanda programada, e atende grupos de diabéticos, hipertensos, tuberculosos, pacientes com hanseníase, idosos, crianças, gestantes, com uma equipe formada pelos seguintes profissionais: médico ou médica, enfermeiro ou enfermeira, técnico ou técnica de enfermagem, dentista e agente comunitário(a) de saúde. Já a enfermeira Lúcia diz que o objetivo da ESF é estabelecer um vínculo entre a saúde e a população, em que a população de cada área atendida está sob a responsabilidade de uma equipe de profissionais.

O discurso de promoção da saúde manifesta-se em palestras, mas principalmente em orientações para que os próprios pacientes tenham cuidado com a saúde. A enfermeira Lúcia usa a metáfora "bater na tecla" para esse trabalho realizado na perspectiva do discurso de promoção da saúde: "a gente tem que tipo bater na tecla dos grupos de acompanhamento das salas de espera que muitas vezes a gente faz e enquanto tem dezesseis pessoas esperando o médico a gente tá lá dando orientação sobre algum assunto.” A enfermeira Lúcia também se refere ao trabalho de prevenção de doenças, "por exemplo aquele idoso que porventura esteja diabético descobriu uma diabetes a gente trabalha com ele preventivamente pra que ele não venha a passar a usar insulina ou então que aquela medicação que ele tá tomando via oral aos poucos ele deixe de tomar e fique com controle somente na dieta através de orientações, né, através de orientações, né, através de orientações de-de conversas de grupos." A repetição do nome "orientações" sugere o valor atribuído ao termo pela profissional de saúde.

\section{A PESQUiSA “O DiálOgo COMO InSTRUMENTO DE INTERVENÇÃo de PROFISSIONAIS dA SAÚde NA RELAÇÃO COM PACIENTES"}

A pesquisa teve início em 2013, com financiamento do PPSUS/CNPq/FUNCAP/SESA - Edital 3/2012, e teve aprovação do Comitê de Ética em Pesquisa da Universidade Federal do Ceará. O objetivo geral foi investigar o diálogo, as práticas discursivas e sociais na interação entre profissionais de saúde e pacientes no contexto da ESF no Ceará e contribuir

\footnotetext{
5 Participaram da pesquisa, além de mim, as seguintes pessoas: profa. dra. Claudiana Nogueira de Alencar (Uece), profa. dra. Nádia Marques Gadelha (Secretaria de Saúde do Ceará), Claudênia de Paula Lemos (Mestranda do Programa de Pós-Graduação em Linguística da UFC), Rebeca Sales Pereira (Mestranda do Programa de Pós-Graduação em Linguística da UFC), e as bolsistas de Iniciação Científica Adelena Leitão Silva e Júlia Salvador Argenta (estudantes do Curso de Letras da UFC).
} 
com uma reflexão sobre a práxis comprometida com o fortalecimento do vínculo terapêutico resolutivo e cidadão de pacientes do SUS. Os objetivos específicos foram: a) analisar o atual modelo interacional-dialógico entre profissionais de saúde e pacientes, com vistas ao fortalecimento do vínculo terapêutico de pacientes e controle de agravos, morbidade e prevenção de mortalidades evitáveis; b) promover oficinas locais para avaliação de ações de promoção de saúde e do diálogo entre a equipe multidisciplinar e os pacientes, para facilitar a realização de metas desejáveis nas diversas políticas da ESF, tais como a adesão e o vínculo terapêutico às ações de cuidado e controle de: hipertensão, diabetes, pré-natal, aleitamento materno, ações de puericultura, saúde da mulher, planejamento familiar, saúde do homem, atendimento a transexuais, gays e lésbicas, questões de gênero e sexualidade; c) fortalecer o vínculo terapêutico como objeto responsivo às demandas de prevenção/controle das doenças crônicas (diabetes, hipertensão) e demais políticas institucionais das principais morbidades no âmbito da saúde coletiva adstritas à ESF nas macrorregiões de saúde do Ceará; e d) examinar a presença da escrita, e como ela se manifesta na comunicação entre profissionais de saúde e pacientes. Neste artigo, examinarei os objetivos 'a' e ' $d$ '.

Foram investigados, nesta pesquisa, cinco municípios do Ceará: Fortaleza e Pacatuba (Macrorregião Metropolitana de Fortaleza), Crato e Salitre (Macrorregião do Cariri), e Croatá (Macrorregião de Sobral). A escolha de tais municípios deu-se devido ao maior e menor IDH de cada macrorregião, de acordo com o censo de 2000, visto que o resultado do censo de 2010 ainda não havia sido divulgado no início de nossas atividades. Cabe acrescentar que o projeto inicial visava pesquisar seis municípios e Sobral era o sexto. Porém, houve uma exigência da Secretaria de Saúde de Sobral de que o projeto fosse submetido ao Comitê de Ética em Pesquisa, que demorou a avaliar o projeto. Em decorrência desse fato, o município de Sobral foi retirado da pesquisa. A seguir, farei uma apresentação dos municípios que serão abordados neste artigo, com base em relatos de observação: Fortaleza, Croatá e Salitre.

\section{Fortaleza}

Trata-se do município maior dentre os cinco, mas o bairro onde a pesquisa foi realizada apresenta mazelas comuns a periferias de grandes centros urbanos. Cercado por um cinturão de favelas, o bairro tem entre seus residentes muitos idosos não alfabetizados e jovens drogados que circulam durante o dia pelas ruas. Em conversas informais e nas entrevistas que realizamos, ouvimos diversas vezes referências à violência do bairro.

\section{Croatá}


Este é o município de menor IDH da região de Sobral, mas aqui não se tem notícia de violência. A equipe multidisciplinar do posto de saúde é recebida com carinho pela comunidade. Geralmente, usa-se a mesa de jantar das residências como cama para o atendimento. Além disso, os pacientes veem com naturalidade a transformação do quarto da família em consultório.

\section{Salitre}

Apesar de ter o menor IDH da região do Crato, é uma cidade pacata, com uma população muito religiosa. São raros os casos de violência. Curiosamente, na igreja matriz, há um dia reservado para mulheres e outro para homens. O uso de tecnologias é visível na praça, principalmente celulares. Também, existem aqui academias ao ar livre, frequentadas principalmente por idosos.

\section{Metodologia}

A metodologia adotada nesta pesquisa foi a etnográfico-discursiva, conforme Magalhães (2000, 2006) e Resende (2009). Nesse tipo de pesquisa, dados orais obtidos, por exemplo, em entrevistas são transcritos e analisados como textos, mas adotando dentre suas técnicas a observação participante, que é característica da pesquisa etnográfica. Foram escolhidas as seguintes técnicas: entrevistas semiestruturadas, observação participante (Angrosino, 2009), relatos de pesquisa, grupos focais, oficinas, coleta de artefatos (textos) e fotos. Neste artigo, os dados derivam de entrevistas, observação participante, relatos de pesquisa e grupos focais.

\section{Participantes}

\section{Fortaleza}

Profissionais de Saúde

\section{Pseudônimo Idade Profissão}

$\begin{array}{lcl}\text { Lúcia } & 33 & \text { Enfermeira } \\ \text { Ricardo } & 55 & \text { Médico } \\ \text { Bruna } & 26 & \text { Médica } \\ \text { Paola } & 35 & \text { Dentista }\end{array}$

Célia $\quad 50 \quad$ Agente Comunitária de Saúde 


\section{Pacientes}

\section{Pseudônimo Idade}

Daniele $\quad 22$

Cristiele $\quad 28$

Joaquim $\quad 51$

Roberta $\quad 65$

Maressa $\quad 69$

Croatá

Profissionais de Saúde

Pseudônimo Idade Profissão

Cíntia $\quad 30 \quad$ Agente Comunitária de Saúde

Elita $\quad 35 \quad$ Técnica de Enfermagem

Patrícia - $\quad$ Dentista

Angelina $\quad 26 \quad$ Enfermeira

Judite $\quad-\quad$ Enfermeira

Pacientes

Pseudônimo Idade

Vilma $\quad 69$

Cindy $\quad 65$

Edyla $\quad 20$

Rejane

Bernabete

Salitre

Profissionais de saúde

Pseudônimo Idade Profissão

Marília $28 \quad$ Dentista 


$\begin{array}{lcl}\text { Rita } & 22 & \text { Enfermeira } \\ \text { Brenda } & 44 & \text { Enfermeira } \\ \text { Diana } & - & \text { Técnica de Enfermagem } \\ \text { Herlon } & - & \text { Médico }\end{array}$

\section{Pacientes}

\section{Pseudônimo Idade}

Iasmin

Áurea

Genifer

Daniela

Jhonata

Os participantes apresentados aqui, 15 profissionais de saúde e 15 pacientea, num total de 30, são os que foram entrevistados, pois nem sempre conseguimos realizar os grupos focais com as mesmas pessoas das entrevistas. Em alguns casos, não foi possível obter a idade dos participantes.

Para a transcrição dos dados, foram adotadas as seguintes convenções:

\begin{tabular}{|c|c|}
\hline Convenção & Correspondência \\
\hline $\mathrm{P}(\mathrm{a})$ & Pesquisadora \\
\hline $\mathrm{M}(\mathrm{a}) 1:$ & Médica 1 \\
\hline$/$ & Interrupção no fluxo da fala \\
\hline$\ldots$ & Pausa na fala \\
\hline$[$ ] & Fala simultânea \\
\hline Letra Maiúscula & Ênfase \\
\hline Entre hifens & Repetição \\
\hline Número & Fala \\
\hline
\end{tabular}

Neste artigo, houve uma simplificação das convenções: $\mathrm{P}=$ Pesquisadora, (inicial) $=$ nome fictício dos participantes. Além disso, foram retirados os números das respostas.

\section{RECONTEXTUALIZAÇÕES E RESSIGNIFICAÇÕES NA PRÁTICA SOCIAL DA ESTRATÉGIA DE SAÚDE DA FAMÍLIA}


A prática social da ESF é uma prática assistencial de promoção da saúde e de prevenção de doenças. Esses são os dois principais discursos da ESF. Neste trabalho, vamos analisar recontextualizações e ressignificações da prática da ESF em 10 entrevistas, com profissionais da saúde e pacientes, realizadas em um posto de saúde de Fortaleza. Esses dados serão complementados com dois grupos focais e relatos de pesquisa. Todos os nomes citados são fictícios.

\section{Exemplo 1}

Nesta entrevista, há vários pontos em que se percebe intertextualidade, nesse caso mais especificamente interdiscursividade, entre a fala da dra. Bruna e os discursos da ESF, que recontextualizam a prática social. Primeiro, a médica faz uma distinção entre atenção primária (atendimento no posto de saúde), secundária (atendimento no hospital) e terciária (atendimento em hospitais especializados). Segundo, ela retoma os discursos de prevenção e promoção da saúde, que são os principais discursos da ESF: “a atenção primária de saúde é uma estratégia válida no sentido de promoção, prevenção e cuidados de atenção primária, tendeu?"

A médica também descreve o que seja a atenção primária: “Então a atenção primária funciona como um suporte da atenção secundária e terciária prevenindo também eventos que façam com que o paciente procure logo o hospital, por exemplo, paciente hipertenso, ele consegue obter as medicações, controlar os valores pressóricos é... aqui na atenção primária, então aqui a gente evita que ele procure hospital só quando tiver com o pique hipertensivo, tendo AVC ou enfartando, entendeu? Ele consegue se beneficiar de-desse cuidado em relação à pressão dele aqui na-no atendimento gratuito e primário." Ao referirse às dificuldades da ESF, ela destaca os exames complementares às consultas e à necessidade de suporte do setor terciário, no caso de os pacientes necessitarem de atendimento especializado de cardiologistas, ortopedistas e neurologistas.

A pergunta feita a todos os entrevistados foi: "Na sua experiência, como é o atendimento no Programa de Saúde da Família?"

\section{Dra. Bruna (B)}

B: É assim, facilidades como é o atendimento na atenção primária, aqui É-é uma coisa que a população precisa, porque não existe é plano de saúde, não existe é... hospital pra todo mundo, ne, Principalmente pra população mais carente. Então assim, a atenção primária de 
saúde é uma estratégia válida no sentido de promoção, prevenção e cuidados de atenção primária, tendeu? Pacientes que não precisam do nível terciário conseguem é ser bem atendido e ter acesso à saúde na atenção primária em que as dificuldades-assim É... vantagens, vantagens é que as pessoas conseguem ter acesso a algumas medicações, conseguem ter acesso a atendimento médico, aqui no posto tem alguns especialistas, então tem cardiologista, tem ortopedista, então muitas vezes quando eu preciso de algum especialista eu consigo aqui no posto, entendeu? Pros meus pacientes, coisas que se eles fossem conseguir particular uma consulta trezentos e cinquenta reais, uma consulta no valô que eles não conseguiriam pagar. Então a atenção primária funciona como um suporte da atenção secundária e terciária prevenindo também eventos que façam com que o paciente procure logo o hospital, por exemplo, paciente hipertenso, ele consegue obter as medicações, controlar os valores pressóricos é... aqui na atenção primária, então aqui a gente evita que ele procure hospital só quando tiver com o pique hipertensivo, tendo AVC ou enfartando, entendeu? Ele consegue se beneficiar de-desse cuidado em relação à pressão dele aqui na-no atendimento gratuito e primário é... dificuldades, as dificuldades é infraestrutura, infraestrutura que a gente observa em todos os lugares é... às vezes falta a medicação da pressão, às vezes não tem paciente que precise de uma consulta com é no caso outras especialidades ou exames como ECO, eletrocardiograma e que a gente não pode oferecer, a gente não tem, ou então assim, vai pra fila, mas na fila ele passa seis meses, sete meses esperando. Então assim, quando o paciente tá um pouquinho mais grave que a gente também não pode oferecer pela rede esses exames, a gente às vezes pede, encaminha para clínicas mais populares ali perto da Santa Casa, que tem um preço mais em conta, que essa é a principal dificuldade que eu vejo aqui na atenção primária conseguir exames é... o paciente muitas vezes não tem nenhum dinheiro pra pagar esse exame de cinquenta reais, porque tem gente que ganha quatrocentos reai por mês, então num tem não tem de onde eles tirar, vai tirar o dinheiro de onde pra pagar esse exame? Então o que tá faltando aindaainda eu acho principais dificuldades. Exame, atendimento terciário falei dois exemplos de cardiologista e dei exemplo do ortopedista, mais... é... neuro... neurologista a gente não tem como conseguir consulta fácil, pra geriatria não tem como conseguir consu-consulta fácil, então assim, tem casos que a gente realmente consegue aqui lhe dá de neuro... de paciente cum... Alzheimer, Parkinson e tudo, mas tem horas que a gente precisa de uma tomografia, entendeu? Precisa de uma coisa assim, e de um acompanhamento por 
especialista, porque a gente sabe que já fica tão específico um quadro clínico tão específico que o médico generalista que sou eu também não consegue suprir todas essas demandas.

Então a gente precisa de um suporte de outras especialidades que a gente encontra muita dificuldade na atenção primária.

\section{Exemplo 2}

Como a dra. Bruna, a agente comunitária de saúde Carla contextualiza a prática social da ESF, conforme van Leeuwen (2008), em termos das condições de elegibilidade (participantes), dos recursos (instrumentos e materiais) e das condições de elegibilidade (recursos), pois ela faz referência à falta de profissionais de maneira bastante enfática, "principalmente pra dar atenção aos acamados, às pessoas idosas que têm dificuldades de se locomover". Carla também diz que "às vezes ainda falta muito é remédio, exames, quer dizer tudo é uma questão de burocracia da unidade, isso aí é ruim"; o que significa falta de recursos (medicamentos e exames). Além disso, ela critica as condições de elegibilidade dos recursos: "uma questão de burocracia da unidade”. Porém, ela destaca o bom relacionamento da equipe.

\section{Agente Comunitária de Saúde (ACS1) Carla}

ACS1: Olha, é sim, ainda deixa muito a desejar, porque ASSIM, eu-eu comecei em dois mil e dez eu só fui ter efetivamente médico na equipe a partir desse ano [2013], de abril desse ano, então assim éé muito assim falta às vezes falta profissional, o problema maior é esse que falta profissional, principalmente pra dar atenção aos acamados, às pessoas idosas que têm dificuldades de se locomover, então assim, isso é um dos pontos críticos, né, mas no geral assim, é contando com a-ê quem tem os componentes da equipe a gente tem bastante acesso a esses compo-às pessoas enfermeira, quando tem médico a gente também tem bastante acesso, a gente pode apesar de que às vezes ainda falta muito é remédio, exames, quer dizer tudo é uma questão de burocracia da unidade, isso aí é ruim. Agora, o relacionamento ao atendimento da equipe é assim é bom, dentro do possível é bom.

\section{Exemplo 3}

No caso do agente comunitário de saúde Pedro, também, nota-se uma intertextualidade com as respostas da dra. Bruna e da agente comunitária de saúde Carla, no que se refere a exames. Segundo Pedro, um resultado de exame pode demorar até dois anos para ser devolvido ao posto, enquanto a marcação de um exame (endoscopia) pode levar até um ano. Da mesma forma que a dra. Bruna, ele critica a dificuldade para obtenção de consultas com especialistas. Ele reconhece, porém, como Carla, que o atendimento é “muito bom”.

\section{Agente Comunitário de Saúde (ACS2) Pedro}


ACS2: Assim, o atendimento do Saúde da Família ele, aqui na unidade, ele é muito bom. O que a gente tá com dificuldade são os caminhamentos para especialização que custa muito, por exemplo se o paciente precisa dum/ tá com problema de dor no estômago o médico precisa de uma endoscopia, o médico pede uma endoscopia a endoscopia demora seis, oito até um ano, então assim não tem como a gente fazer muita coisa quando sai daqui da da nossa esfera, quando chega na na secundária o povo fica com confusão porque num volta a ter retorno pra gente, então o tá o que mais deixa a gente assim é isso daí que a gente pede um um ixame, e esse ixame precisa voltar pra mão do médico. Passa um ano até até dois anos pá voltá pu nosso (ininteligível). Se a pessoa tem dor de cabeça constante, a gente num vai poder ficar na admissão passa uma mão, passa ota mão (ininteligível) dor de cabeça tá pá tratar com outro tipo de medicação, né? Então assim, se tem o neurologista, a pessoa tá na fila de espera e demora e demora a pessoa fica naquele sofrimento, então eu acho assim, a única coisa que tinha que mudar é só esse essa consulta especial ser um pouquim mais rápido aí sim, aí o programa ficava perfeito se não fosse esse obstáculo.

\section{Exemplo 4}

Na fala da dra. Paola, que é dentista, há novas informações sobre a prática da ESF: é um "atendimento sistematizado" e os atendimentos podem ser por "demanda livre", "demanda programada" ou por grupos (por exemplo, diabéticos, crianças, gestantes). Há uma intertextualidade entre a fala da dra. Paola e a da enfermeira Lúcia (Exemplo 5), pois ambas se referem à equipe multidisciplinar. A enfermeira apresenta a composição da equipe: dentista, médico ou médica, enfermeiro ou enfermeira, técnico ou técnica de enfermagem e agente comunitário de saúde.

\section{Dra. Paola (dentista/D)}

D: Como é? É um atendimento sistematizado, né, que tem A DEMANDA LIVRE a gente atende a demanda livre e atende uma demanda programada e atende através de grupos, né, grupos de diabético, grupo de crianças, gestantes sempre em conjunto com a equipe.

\section{Exemplo 5}

Nesta entrevista, a enfermeira Lúcia recontextualiza a prática social da ESF em seu objetivo, que é o de "criar um vínculo entre a saúde e a população”. O vínculo é muito valorizado pelos profissionais de saúde, e em um dos grupos focais deste estudo, há uma discussão sobre essa questão, estabelecendo uma relação intertextual com a fala da enfermeira Lúcia. Outro ponto destacado pela enfermeira é a definição da função dos agentes comunitários de saúde, que são "elos" entre o posto de saúde e a população, pois eles residem na mesma comunidade: "ele vai ser o-o-o elo maior entre a população e a unidade de saúde, onde ele vai trazer todos os problemas, é lá onde ele vai escutar, onde ele vai observar as 
necessidades da população e vai trazer pra gente que tá dentro da unidade, os profissionais, é... pra que a gente possa trazer soluções."

\section{Enfermeira Lúcia (L)}

L: Bom, o programa de saúde da família que agora é Estratégia de Saúde da Família, ele tem a... o objetivo de-de fazer um-um criar um vínculo entre a saúde e a população, então cada equipe é responsável por uma determinada área, certo, e toda aquela população que reside ali é de responsabilidade dos profissionais da equipe. A equipe é composta por: dentista, médico, enfermeiro, os técnicos de enfermagem de saúde bucal e os agentes comunitários de saúde, onde cada um tem papel em relação relacionado com a comunicação. $O$ agente de saúde, ele reside na mesma área dessa população, então ele vai ser o-o-o elo maior entre a população e a unidade de saúde, onde ele vai trazer todos os problemas, é lá onde ele vai escutar, onde ele vai observar as necessidades da população e vai trazer pra gente que tá dentro da unidade, os profissionais, é... pra que a gente possa trazer soluções. É mais ou menos isso.

\section{Exemplo 6}

As frases "Deixa muito a desejá", "Não teve médico. Tô com a pressão 437, cadê? Cadê o atendimento? Deixa muito a desejá", "deveria tê um atendimento melhor né? 437 na glicemia é ruim. Fazê o quê? $20 \mathrm{ml}$ de insulina" estabelecem intertextualidade com os profissionais de saúde em relação à falta de profissionais, mas em momento algum a paciente reconhece vantagens no atendimento da ESF em relação a outros. Na verdade, a tendência dos pacientes é registrar que todos os atendimentos de saúde públicos são ruins. Note-se a repetição da frase "Deixa muito a desejá", que ressalta a forma negativa com que a paciente vê o atendimento.

\section{Paciente Roberta (R)}

\section{R: Deixa muito a desejá. \\ P: Como assim?}

R: Por quê? Porque sim. Cadê? Não teve médico. Tô com a pressão 437, cadê?, cadê o atendimento? Deixa muito a desejá. Que não tem pra eles, deveria tê outros, deveria tê um atendimento melhor né? 437 na glicemia é ruim. Fazê o quê? (ininteligível) $20 \mathrm{ml}$ de insulina (ininteligível).

\section{Exemplo 7}

Nesta entrevista, a frase "Olha, eu num vejo muita melhoras não" e as frases que começam com "em alguns lugares em que eu já-já estive, euuu num vejo muita essas coisa não, eu vejo muito descaso no caso da saúde, os profissionais também num dá um atendimento adequados, né, então não vejo essas coisa muito" até a narrativa sobre a morte 
do marido da paciente Maressa guardam uma forte relação intertextual com a crítica feita pela paciente Roberta: veja-se a relação entre a negação da melhoria no atendimento ("Olha, eu num vejo muita melhoras não") e a afirmação categórica ("eu vejo muito descaso no caso da saúde"), que generaliza o mau atendimento a todo o Sistema Único de Saúde (SUS). Há aqui uma gradação da intertextualidade, da negação à afirmação e, finalmente, ao desfecho da narrativa, com a morte do marido de Maressa, segundo ela diz de "fome", com ênfase na sílaba inicial do nome "fome", criando um efeito dramático na intertextualidade. Destaca-se, também, a crítica aos profissionais, que, de acordo com a paciente, não dão um atendimento adequado.

\section{Paciente Maressa (Mar)}

Mar: Olha, eu num vejo muita melhoras não. Quer dizer...parece que tem algo que assim a gel eu tô observando que aqui no caso aqui como a gente só vem aqui no posto, né, aqui que a gente éé em alguns lugares que eu já-já estive, euuu num vejo muita essas coisa não, eu vejo muito descaso no caso da saúde, os profissionais também (ininteligível) num dá um atendimento adequados, né, então não vejo essas coisa muito, eu vejo um problema também que aconteceu com meu marido, ele doente e foi um descaso, meu marido ficou internado lá nesse hospital, passou vinte dias, assim, sabe?, sem um atendimento médico, os profissionai da saúde não atendiam de acordo com o que era necessidade dele, e ele era considerado paciente grave, mas pra eles AINDA não era grave, tanto que meu marido faleceu assim, sabe?...praticamente de/ de FOme, ficou on/ doze dias éé só num jejum zero, dieta zero, dieta zero, porque ele tinha que fazer uma cirurgia de uma de umaal ele tinha "ca” de boca, né, então ele precisava se tê de colocá uma sonda gástrica aí durante DOZE dias ele ficou sem tomar UMA ÁGUA jejum direto, direto, direto e aí eu acredito que ele faleceu por conta de um atendimento mais adequado, né, não sei, eu penso assim, né, pode ser que eu esteja errada, né? E o atendimento assim da saúde eu num num vejo essas coisa muito boa não. É bom que melhore mais um pouquinho, né, é o que a gente tá esperando, né, o governo vê se faz alguma coisa, né?

\section{Exemplo 8}

Aqui, as frases "Por mim é PÉSSIMO”, "Por falta de despreparo: [preparo] dos-dos atendente" e "Num...tão nem aí pa ninguém" estabelecem intertextualidade com as respostas dos outros pacientes, na crítica ao atendimento da ESF. Nesse caso, a crítica estende-se aos 
atendentes, com a negação (“Num tão nem aí pa ninguém”). A ênfase em "péssimo" reforça a crítica.

\section{Paciente Felipe (F)}

\section{F: Por mim é PÉSSIMO.}

P: Por quê?

\section{F: Por falta de despreparo: dos-dos atendente. Num...tão nem aí pa ninguém.}

\section{Exemplo 9}

Quando a paciente Cristiele diz que o atendimento "é horrive", há uma intertextualidade com a frase "é péssimo", usada pelo paciente Felipe, e com as frases "Deixa muito a desejá", de Roberta e "eu vejo muito descaso no caso da saúde", de Maressa.

\section{Paciente Cristiele (C)}

\section{C: $\boldsymbol{E}$ horríve.}

\section{Exemplo 10}

A frase "É um pouco lento", como nos Exemplos 6, 7, 8 e 9, tem um sentido negativo, relacionando-se com eles na crítica ao atendimento. Além disso, a paciente Débora, da mesma forma que a paciente Maressa, generaliza sua crítica: “Tudo são lento...os atendimento”.

\section{Paciente Débora (D)}

D: É um pouco lento, né, mas todo hospital que a gente vai todos são dum jeito só. Nono...no questão de atendimento, todo hospital é de um jeito só. É, você sai daqui vai pro Hospital Geral, vai pro Hospital de Centro pensando que é melhor má é a merma coisa. Tudo são lento...os atendimento.

\section{Exemplo 11}

Neste exemplo do Grupo Focal realizado em Croatá, a enfermeira Angelina recontextualiza a prática social da ESF em termos do vínculo que precisa ser estabelecido entre os profissionais de saúde e os pacientes (“famílias"). Aqui também há intertextualidade; contudo, ela opera como ruptura. É como se Angelina dissesse: fala-se X sobre a ESF, mas para mim, o que é fundamental é o vínculo terapêutico ("o PSF ele é pra ter um segmento, é pra ser uma coisa de longo prazo, profissional é pra estar dentro da unidade, ele acompanha famílias"; "o vínculo, o PS/ o Programa de Saúde da Família ele é pra ter um vínculo com as famílias"). 
Angelina também aborda o "medo" dos pacientes, que às vezes não tomam os medicamentos da forma correta, e após relatar uma breve narrativa sobre uma paciente, diz que eles sentem-se "acuados", "é como se eles tivessem levando carão", pois têm "medo do médico”. Já a agente de saúde Isamara discorda da colega Cíntia, que falou antes dela, e da enfermeira Angelina, pois de acordo com ela, os pacientes “conversam", e as contradiz ao atribuir o problema de comunicação aos médicos: "as pessoas chegam vai no consultório, quando chegam lá, aí o-o médico tá ali atrás dum birô, muitas vezes nem olha pro paciente realmente, né, aí diz, o-o que é seu problema, aí baixa a cabeça ali, a pessoa nem chega a dizer realmente o-o que que é o problema né, aí a g/ escreve aí e pronto, tá dispachada aí assim..."

\section{Grupo Focal de Profissionais da Saúde em Croatá}

Pesquisadora 1: Alguém gostaria mais de falar?

Agente de Saúde Isamara: Não assim, é-é (risos) eu disco/ eu discordo dela nessa parte quando ela diz assim éé que o profissional, o médico, né, ééé [ou a enfermeira] é ou a enfermeira nuиum o-o paciente num conversa né e tal, conversa sim, só que tem muitos profissionais que realmente, né, as pessoas chegam vai no consultório, quando chegam lá, aí o-o médico tá ali atrás dum birô, muitas vezes nem olha pro paciente realmente, né, aí diz, o-o que é seu problema, aí baixa a cabeça ali, a pessoa nem chega a dizer realmente oo que que é o problema né, aí a g/ escreve aí e pronto, tá dispachada aí assim... por, isso aqui que muitos muitos pacientes diz, ai eu num gosto de me consultar com médico fulano ou médica fulana, porque ela nem olha pra gente, né, ela nem escuta direito o que a gente tem pra-pra falar, aí tem toda razão, né, que se a pessoa vai abrir a boca pa dizer uma palavra, num diz nem a primeira quanto mais o resto, né [certo] então é isso.

Pesquisadora 1: Alguém mais?

Enf. Angelina: É, como éé a Sandy falou anteriormente [a Cíntia], a Cíntia, é como acontece, porque assim, ALGUNS profissionais são assim e eles acabam generalizano, entendeu [exatamente] eles acabam generalizando achando que todos são assim, mas é cultural, eles tem medo, por mais que a gente diga/ eu tinha um paciente antes que ela as vezes até porque ela diz não tão bem, porque eles não fazem o tratamento correto ou coisa do tipo, eles ficam com medo, eu tinha uma paciente que ela era hipertensa e ela não fazia o tratamento correto 
e ela sempre tava com a pressão alterada, mas ela não ia às consultas e uma vez o agente comunitário de saúde me disse, ela disse assim, eu acho que a Angelina fica com raiva de mim, porque eu tô com pressão alta, só que jamais eu vou sentir raiva de um paciente porque eu tô com a pressão alta, eles podem achar que no momento que eu estou orientando, por mais que você saiba falar, mas no momento que a pessoa tá orientando é como se eles tivessem levando carão, digamos assim, eu por exemplo eu não acho que eu tenho mais idade pra levar carão, eu não gosto, então de repente pode acontecer isso com o paciente, ele sabe, às vezes ele não tem, ele negligencia a saúde e se sente acuado, digamos assim, pra não tá sendo chamado atenção, tem gente que não gosta, então ALGUNS casos, né, a gente não pode generalizar tudo como eles acabam fazendo, eles ficam temerosos, por conta dal porque a situação em si, já é assim, você vai pra consulta, ele já tem o medo do médico, e eu penso eu penso que seja por causa disso, mas é como eu falei, o PSF ele é pra ter um segmento, é pra ser uma coisa de longo prazo, profissional é pra estar dentro da unidade, ele acompanha famílias e é pra adquirir a confiança de cada um, de cada usuário [o vínculo terapêutico] o vínculo, o PS/ o Programa de Saúde da Família ele é pra ter um vínculo com as famílias, [é é exatamente] natural é pra ser isso.

\section{Exemplo 12}

Neste exemplo, do Grupo Focal de Pacientes de Salitre, os pacientes discordam a respeito do atendimento dos profissionais, ressignificando-o de várias formas. Enquanto Genifer considera que o atendimento é bom ( "Eu na minha parte acho tudo bom”), Jhonata e Daniela discordam. Para Daniela, o médico "é muito estúpido, num atende as pessoa bem, muito ignorante”. Por sua vez, Jhonata reclama do médico por não entender o que ele diz e nem a escrita da receita ("Eu num entendo." "Num vou mentir não, num tô enten/ desse médico aqui eu num tô entendendo é nada tá com três veze que ele pede exame pra mim, não, vou fazer mais não, deixa eu queto quando ele pedir, não doutor num venho mais não, ai eu puxo proutro médico vou fazer (ininteligível)... eu num vejo futuro aqui não (ininteligível) só isso.")

\section{Grupo Focal de Pacientes em Salitre}

Pesquisadora 1: E vocês como fazem pra resolver os problemas de saúde? 
Genifer: Eu na minha parte acho tudo bom, né, ele atenderam bem, atende minha mãe bem, todos, só atende bem, né, tenho o que dizer dele lá e de-de prefeito também não, tudo bom, pa minha parte é, né.

Jhonata: Já eu num acho não

Genifer: Mas eu acho... tem nada que se dizer sobre ele.

Daniela: $E u /$

Genifer: (ininteligível) que chego lá no hospital sou tratada tudo bem, eles tudo, bem, é doutor Fernando, doutor Geraldo, qualquer um, ele aí, num vou mentir né, [num instante fala coisa boa, porque sabe que tem gente ouvindo] num vou acusar o que eu num sei né, eu num sei, são tudo bom, pra mim da minha parte, da saúde de minha mãe, e-e pra minhas irmã tudim eles atende tudo bem, doutor Fernando, como o outro, tem o que dizer não.

Daniela: Bom, eu-eu reclamo do doutor Fernando porque tem... às vez que fui lá ele é muito estúpido, num atende as pessoa bem, muito ignorante, isso que tenho a dizer.

Pesquisadora 1: E como a senhora faz pra resolver seus problemas de saúde?

Daniela: Á... еи еи-еи-еи еи пит vou, quando eи posso pagar o médico particular, é assim.

Pesquisadora 1: Eee como vocês entendem as receitas médicas?

Jhonata: Eu num entendo.

Pesquisadora 1: Não entende por quê?

Jhonata: Num vou mentir não, num to enten/ desse médico aqui eu num tô entendendo é nada tá com três veze que ele pede exame pra mim, não, vou fazer mais não, deixa eu queto quando ele pedir, não doutor num venho mais não, ai eu puxo proutro médico vou fazer (ininteligível)... eu num vejo futuro aqui não (ininteligível) só isso.

Resumindo, a análise aponta que a prática assistencial da saúde recontextualizada por profissionais de saúde e pacientes é complexa, híbrida, ora é uma coisa, ora outra. Distintos aspectos são recontextualizados, há intertextualidade em suas falas, mas há também discordâncias e contradições. Existem diferenças entre profissionais e pacientes, mas também entre os próprios profissionais. Essas diferenças e relações contribuem, na ordem do discurso 
da saúde, para conferir uma espécie de instabilidade aos discursos de promoção da saúde e prevenção de doenças. Essa instabilidade certamente afeta as identidades profissionais no contexto complexo da saúde, forjando-as na recontextualização híbrida da prática assistencial.

\section{CONSIDERAÇÕES FINAIS}

Este artigo examinou o conceito de recontextualização, buscando relacioná-lo ao hibridismo da modernidade posterior. Como resultado da análise, é possível apontar: 1) a existência de intertextualidade nas falas de profissionais de saúde e pacientes no processo de recontextualização da prática assistencial de saúde; 2) ao lado da intertextualidade, é possível identificar também diferenças e oposições, que indicam ressignicações da prática assistencial. Tais ressignificações, para além de sugerirem uma heterogeneidade de significados, indicam instabilidades que constroem identidades profissionais em meio a tensões na tentativa de estabelecimento do vínculo terapêutico com pacientes.

Recebido em: maio de 2015 Aprovado em: outubro de 2015 mizabel@uol.com.br

\section{REFERÊNCIAS}

ALENCAR, C. N. de. O mito da representação nos estudos críticos da linguagem. In: PINTO, J. P.; FABRÍCIO, B. F. (Orgs.) Exclusão social e microrresistências: a centralidade das práticas discursivo-identitárias. Goiânia: Cânone Editorial, 2013, pp. 35-56.

ALTHUSSER, L.; BALIBAR, E. Reading Capital. Londres: New Left Books, 1970.

ANGROSINO, M. Etnografia e observação participante. Trad. J. Fonseca. Porto Alegre: Artmed, 2009 [2008].

BALL, S. J. Global policies and vernacular politics in education. Currículo sem Fronteiras, 1 (2) 99116, 2001.

BERNSTEIN, B. The structuring of pedagogic discourse. Londres: Routledge, 1990.

BLOMMAERT, J. Discourse. Cambridge: Cambridge University Press, 2005.

FAIRCLOUGH, N. Critical Discourse Analysis: the critical study of language. 2a ed. Londres: Longman, 2010.

. A dialectical-relational approach to Critical Discourse Analysis in social research. In:

WODAK, R.; MEYER, M. (Eds.) Methods of Critical Discourse Analysis. Londres: Sage, 2009, pp. 162-200.

. Analysing discourse: textual analysis for social research. Londres: Routledge, 2003. 
Discurso e mudança social. Coord. trad., rev., pref. I. Magalhães. Brasília: Editora Universidade de Brasília, 2001 [1992].

FOUCAULT, M. A ordem do discurso: aula inaugural no Collège de France, pronunciada em 2 de dezembro de 1970. Trad. L. F. de A. Sampaio. São Paulo: Edições Loyola, 1996 [1971]. 1987.

. A arqueologia do saber. Trad. L. F. B. Neves. 3a ed. Rio de Janeiro: Forense-Universitária,

GIDDENS, A. Modernity and self-identity. Cambridge: Polity Press, 1991.

GOMES, M. C. A. Ação social midiatizada: analisando a recontextualização de um evento social. Linguagem em (Dis)curso, 10 (2): 293-313, 2010.

HALLIDAY, M. A. K. An introduction to functional grammar. 2a ed. Londres: Edward Arnold, 1994 [1985].

. Language as social semiotic. Londres: Edward Arnold, 1978.

LOPES, A. C. Política de currículo: recontextualização e hibridismo. Currículo sem Fronteiras, 5 (2): 50-64, 2005.

MAGALHÃES, I. Discurso e identidades: exotismo e domínio violento. Cadernos de Linguagem e Sociedade, 11 (1): 13-37, 2010.

. Discurso, ética e identidades de gênero. In: MAGALHÃES, I.; GRIGOLETTO, M.;

CORACINI, M. J. (Orgs.) Práticas identitárias: língua e discurso. São Carlos: Claraluz, 2006, pp. 7196.

. Eu e tu: a constituição do sujeito no discurso médico. Brasília: Thesaurus, 2000.

et al. O diálogo como instrumento de intervenção de profissionais da saúde na relação com pacientes. Fortaleza: PPSUS/FUNCAP/CNPq/SESA - Edital 3/2012. Relatório de Pesquisa, 2014.

RESENDE, V. de M. Análise de Discurso Crítica e Realismo Crítico: implicações interdisciplinares. Campinas, SP: Pontes, 2009.

VAN LEEUWEN, T. Discourse and practice: new tools for critical discourse analysis. Oxford: Oxford University Press, 2008. 